\title{
The Exit of Residential Mobility or the Voice of Political Action? Strategies for Problem Solving in Residential Communities ${ }^{1}$
}

\author{
MARK VAN VUGT ${ }^{2}$ \\ University of Southampton \\ Southampton, United Kingdom \\ PETER JOHN
Birkbeck College
London, United Kingdom
}

\author{
KeITH DOWDING \\ London School of Economics \\ London, United Kingdom \\ ERIC VAN DIJK \\ University of Leiden \\ Leiden, The Netherlands
}

\begin{abstract}
This research investigated 2 action strategies for residents to deal with dissatisfying community services: moving out of the community (exit), or communicating dissatisfaction to local authorities (voice). Data were used from a population movement survey conducted among 1,529 households in 3 major cities in the United Kingdom in 1997. Employing concepts from interdependence theory (Kelley \& Thibaut, 1978), we predicted that dissatisfaction with community services would lead to more exit and voice responses. Furthermore, exit was predicted to be dominant among residents who, for diverse reasons, were less dependent; and voice was predicted for residents who were more dependent on the community. These predictions were supported, and the relevance of these findings for understanding community stability and improvement is discussed.
\end{abstract}

How do residents solve problems within their local community? How do they respond, for example, when they perceive a decline in the quality of local community services, such as schools, health and leisure facilities, libraries, and police? Will residents improve their situation by moving to an area offering better facilities or by communicating dissatisfaction to local authorities, thereby hoping that services will be improved?

The social psychological literature has addressed several aspects of community action and civic participation, without yet resolving the above issues completely. In social justice research, for example, social psychologists have examined which factors shape citizens' evaluation of authorities. Several researchers have emphasized the importance of satisfaction with the material

1This research was made possible by Grant \#9000 236658 from the U.K. Economic and Social Research Council to Keith Dowding and Peter John.

${ }^{2}$ Correspondence concerning this article should be addressed to Mark Van Vugt, Department of Psychology, University of Southampton, Southampton S017 1BJ, United Kingdom. E-mail: mvv@ soton.ac.uk

Journal of Applied Social Psychology, 2003, 33, 2, pp. 321-338.

Copyright (C) 2003 by V. H. Winston \& Son, Inc. All rights reserved. 
outcomes that people receive from authorities (Adams, 1965; Crosby, 1976; Hollander, 1985). Other research stresses the importance of receiving fair treatment in how individuals evaluate authorities (Folger, 1977; Tyler \& Lind, 1992). However, from these theories, it is quite difficult to predict what specific behavioral strategies residents might undertake when they are dissatisfied with services provided by local community authorities (cf. Tyler \& Smith, 1998).

Other areas of social psychological research have examined, in great detail, behavioral responses to dissatisfaction. Frequently, a distinction is made between individual and collective action strategies. Social dilemma research, for example, tends to concentrate on individual actions in response to community problems by studying people's willingness to engage in voluntary cooperation (Dawes, 1980; Komorita \& Parks, 1994). Recently, social dilemma researchers also have started to take an interest in collective actions to tackle community problems; for example, by empowering local authorities (Tyler \& Degoey, 1995; Van Vugt \& De Cremer, 1999; Van Vugt, Snyder, Tyler, \& Biel, 2000). Finally, research on social and political movements (Kinder, 1998; Klandermans, 1997; Tyler \& Smith, 1998) has focused almost exclusively on collective efforts to tackle community problems, such as through voting in local elections, participation in demonstrations, or membership of local interest groups. Although the distinction between individual and collective action strategies is useful for heuristic purposes, we believe it is not the only way to classify residential strategies to overcome community problems.

In the present study, we propose an alternative framework for understanding the way residents try to solve community problems. In dealing with a decline in community services, for example, residents can either collaborate with authorities to improve these services - what will be referred to as the voice strategy-or they can leave their community and move into a community with better facilities-what will be referred to as the exit strategy. Obviously, residents can (and often do) decide to do nothing about these problems. Yet, when dissatisfaction about community services grows because the quality of local schools and health services deteriorates rapidly, for instance, residents might have no choice but to do something about the situation. In this study, we present a social psychological model to understand when residents choose either an exit strategy or a voice strategy in response to dissatisfaction with community services.

\section{Exit or Voice? Two Community Action Strategies}

Our framework is inspired by the seminal work of economist Albert Hirschman (1970) on consumer responses to a decline in product quality of firms and states. Following Hirschman's argument, residents might react in two different ways when they are dissatisfied about local community services and wish to do something about the situation: Either they exit or they voice. Exit can be defined formally as 
an attempt to escape from a problematic situation, such as moving out of a bad neighborhood (cf. the voting-with-your-feet principle; Tiebout, 1956). Voice, in contrast, pertains to any attempt to turn around a problematic situation; for example, by communicating dissatisfaction to local authorities and urging them to undertake community-improving actions. ${ }^{3}$

Both exit and voice are active problem-solving strategies, in contrast to simply getting used to these problems. Yet, they differ in both their means and ends. First, the exit of residential mobility is, by and large, an individual response to community problems, whereas the voice of political action can either be conducted individually (contacting the local authority or council) or collectively (electing a local council). ${ }^{4}$ Second, whereas voicing is generally constructive because residents make an effort to help improve their local community, exit is generally destructive for the community. Indeed, residential mobility, if it occurs frequently, can lead to a further decline of the community because communities are refrained from individuals who could be actively engaged, thus leaving behind a group of residents who suffer in silence (Dowding, John, Mergoupis, \& Van Vugt, 2000; Orbell \& Uno, 1972). Hence, the distribution of exit and voice strategies among residents might have important implications for the stability and welfare of communities. It is therefore paramount to investigate when residents use these community problem-solving strategies.

\section{An Interdependence Analysis of Exit and Voice}

We propose a generic social psychological framework for understanding the use of these community problem-solving tactics (exit or voice), which is based on interdependence theory (Kelley \& Thibaut, 1978; Rusbult \& Van Lange, 1996). The main assumption is that the residential use of exit/voice strategies in response to a decline in community services is shaped by two separate aspects of the relationship between residents and their local community: degree of dissatisfaction (with community services), and degree of dependence. According to the model, dissatisfaction predicts whether residents will come into action, as compared to doing nothing, whereas dependence predicts whether residents will decide to use an exit or voice strategy.

3 Voice pertains to any activity, individual or collective, to communicate dissatisfaction to authorities in order to bring a change in the current state of affairs. It should be distinguished from voice in a procedural/legal sense, where it refers to a structural opportunity to have a say in the decision-making process of the authority (Folger, 1977; Tyler \& Lind, 1992). Obviously, the two voices are linked, because voice procedure should facilitate the emergence of voice responses.

${ }^{4}$ Larger residential communities in the United Kingdom are organized into city or district councils. A political body, called the Council, which is responsible for the administration of the community, governs the council. The Council consists of a number of councilors, who are representatives from the community who make the decisions regarding community policy, services, and finances and who are elected by the community. 
Whether residents will do something in response to the local service provision is largely determined by the degree of dissatisfaction they are experiencing. Satisfaction is judged against various criteria, such as how well the local community services fulfill people's personal interests (jobs, leisure, and health services), their family's interest (education for children), or the interests of their particular street or neighborhood within the larger community (access to public transportation). Degree of dissatisfaction, however, might not be derived only from the actual state of community services, but also from the expectation about what residents think that their quality should be (comparison level; Kelley \& Thibaut, 1978) or what residents feel that they are entitled to; for example, given the local tax regime (relative deprivation; Crosby, 1976).

It is unlikely that all residents will respond to a decline in services in exactly the same way, however. Residents' evaluation of the relative costs and benefits of different action strategies will vary with the opportunities they think they have for change. Following interdependence theory, a key condition for change is the dependency of residents on the community and its services. Dependency can be interpreted here as the extent to which residents believe they are restricted in exit opportunities, hence are forced to stay in the community to fulfill their needs in terms of accommodation, health, education, and leisure. Accordingly, dependence is inversely related to the availability of options to move elsewhere.

Exit opportunities might be restricted for a variety of reasons (e.g., economic, physical, cultural, social). For example, urban studies (e.g., Orbell \& Uno, 1972; Rossi, 1980) have indicated that residential mobility patterns are influenced by sociodemographic factors, such as age (younger residents generally are more mobile), income (mobility increases with wealth), family situation (presence of children restricts mobility), and current housing (property owners are less likely to move than are people who rent). A conglomerate of different social and demographic variables thus influences residents' dependency. In combination, these factors presumably determine whether residents respond to poor community services by exiting the community or, when this is largely impossible, by using a voice strategy to tackle the decline.

Taken together, we first predict that dissatisfaction is related to both an increase in the use of exit and voice strategies. Furthermore, weakly dependent residents are, overall, more likely to use exit as a residential strategy; whereas highly dependent residents will use voice more often. Highly dependent residents are expected to use voice more, regardless of their actual dissatisfaction with the services, because their voicing keeps the local authorities alert, thus preventing a possible future decline in community services.

Finally, it could be that use of these strategies (exit and voice) among weakly and highly dependent residents intensifies with a growing dissatisfaction about community services. With growing dissatisfaction, more residents will exit, but presumably only those who are weakly dependent. Conversely, highly dependent 
residents who are dissatisfied do not have that choice. They either must wait passively for things to change or try to improve the situation by voicing their dissatisfaction to local authorities. Thus, for exploratory purposes, we also examine whether there are interactive effects of dissatisfaction and dependence that account for residents' use of these action strategies.

\section{How the Present Study Builds on Previous Research}

This study extends and complements previous research on residential mobility and community action, published in the political science literature. For example, Orbell and Uno (1972) used a similar framework to understand residents' responses to urban problems in a metropolitan community in the United States in the 1960s. Among other issues, these researchers were interested in contrasting the reactions of White and Black residents to a range of self-reported problems within inner-city communities (e.g., crime, safety, housing). They hypothesized and found that mobility and political action intentions were more prevalent when neighborhood problems were perceived as more severe. Furthermore, they showed that the dominant preference for White residents was to leave the area and move into the suburbs. In contrast, Black residents preferred taking actions to address neighborhood problems (e.g., writing letters, participating in local politics). The researchers attributed these results to a differential availability of exit opportunities, with White residents having access to a greater range of alternative residential communities than Black residents.

The present study extends this earlier work in four ways. First, by studying exit voice patterns among residential communities within three major cities in the United Kingdom (London, Manchester, and Birmingham) almost four decades later, our study could add to the credibility of their findings and interpretation. Second, whereas we also rely on expressed mobility intentions rather than actual behavior, unlike previous work we employ a self-reported behavioral measure of voice whereby we ask residents whether they have actually been in contact with the local authorities. Third, rather than focusing on community problems in general, our study concentrates on the perceived quality of local community services. Because this problem is presumably more controllable than other neighborhood problems (e.g., unemployment), voicing could be perceived as a viable residential strategy. Yet, this also means that our predictive model might not account for a great deal of variance in exit and voice because there can be many different reasons for using these action strategies, beyond poor quality of services. A final, perhaps most important, contribution of our study is that by using concepts from interdependence theory (satisfaction and dependence) we provide a theoretical basis for specifying the conditions under which exit versus voice strategies are likely to be used within a residential context. 


\section{Method}

\section{Participants and Procedure}

We used data from a study on population movement that was commissioned by the London School of Economics with financial support from the Economic and Social Research Council (Mergoupis, Dowding, \& John, 2000). That study was developed to assess residential mobility patterns in metropolitan areas. Interviews were held in 1997 with a total of 1,529 households in three metropolitan areas in England: London (480), Birmingham (504), and Manchester (545). The interviews were conducted door to door. Addresses were contacted up to four times on different days and times, including evenings and weekends. This led to an acceptable response rate of $65 \%$, culminating in a total of 1,529 interviews. The survey respondent was always a member of the core household.

A stratified sampling procedure was used for the survey. The sampling of households proceeded in two phases. First, a stratified sampling procedure was used to select 12 to 13 local communities within each of these cities. Strata were defined according to the distribution of owner-occupied and rented households within these areas (data were obtained from the 1990 Census). The method ensured that there would be a diversity of metropolitan communities represented in the sample. At the second stage of the sampling, addresses were randomly selected from the register of zip codes corresponding to each local community.

\section{Questionnaire}

Participants were instructed that the survey was commissioned by the London School of Economics to find out why people choose to live in a particular neighborhood. The questionnaire consisted of 61 questions in total and was divided into two parts. One part (31 questions) was designed to provide sociodemographic information about the sample (e.g., age, household, family composition) and the other part (30 questions) was designed to assess residents' evaluation of their living situation and their mobility patterns (for details, see Mergoupis et al., 2000). For the purpose of this study, we selected those items that addressed the evaluation of community services as provided by the local council/authority, as well as the use of exit and voice strategies. Responses were assessed using different scales, but all included a "Don't know" option. These responses were treated as missing values in the analyses.

\section{Measures}

The following items were selected to create indexes of dissatisfaction, dependence, voice, and exit. Unfortunately, for some of the constructs there was only a single-item measure available.

Dissatisfaction with community services. This was measured by one general item: "At your current address, in general how satisfied or dissatisfied are you 
with the local council's provision of services?" This item was rated on a 5-point scale ranging from 1 (very satisfied) to 5 (very dissatisfied). To help the participants decide, we included a list of services provided by the local council, such as libraries, health services, state schools, refuse collection, leisure services, street cleaning, social services, and the police.

Dependence on the community. We used demographic information from the survey to construe an objective index of dependence (for a similar procedure, see Rusbult \& Lowery, 1985). Based on some well-known factors affecting mobility (Rossi, 1980), the following household characteristics were considered to be relevant: (a) having children between the ages of 5 and 18 years $(0=N o, 1=Y e s)$; (b) renting (0) or being a homeowner (1); (c) being single (0) or living with a partner (1; i.e., married or cohabiting); (d) being 41 years of age or younger $(0)$ or being older than 41 years $(1$; i.e., 41 was the median age split in the sample, and older residents are generally less mobile; Rossi, 1980); (e) having a member of the household in regular paid employment $(0)$ or no members of the household in regular paid employment (1). Accordingly, dependence scores varied between 0 and 5 , with a maximum score of 5 (highly dependent) for a household with the core including two adults over the age of 41 years, who owned their house, had school-age children, and had no paid employment. ${ }^{5}$

Voice activities. Voice was measured by three behavioral items. The stem "At your current address, have you ..." was followed by the items ". . . contacted your local councilor?"; ". . . had any dealings with council employees about council services?"; and “. . . voted in a local election?" $(0=$ No, $1=$ Yes $)$. An overall voice index was construed by adding up the three item scores (minimum score $=0$, no voice; maximum score $=3$, full voice). This scale had a modest reliability $(\alpha=.55)$. Therefore, we also used these items separately in our analysis.

Exit intention. Finally, the intention to move was measured by the following item: "Which of the following best describes what you think you will do in the next 2 to 3 years?" $(1=$ definitely stay in this home; 2 = probably stay in this home; 3 = probably move from this home; or $4=$ definitely move from this home). This is a standard measure in urban research (Orbell \& Uno, 1972). In addition, we asked all potential movers (scores of 3 or 4 ) whether they were considering a move out of this council area $(1=$ Yes, definitely; $2=$ Yes, maybe; or $3=N o)$. Those people who gave a response of $3(\mathrm{No} ; \mathrm{N}=114)$ were excluded from further analyses. ${ }^{6}$

${ }^{5}$ Because the measure of dependence was derived from objective rather than subjective estimates, and because it was based on information about respondents' demographic characteristics, an assessment of the reliability of this variable is meaningless. Such an analysis would assess, for example, the relationship between having children and owning/renting a house.

${ }^{6}$ Moving is defined here as interjurisdictional moving-in other words, moving from one community to another. Moving within a community, intrajurisdictional moving, cannot be regarded as true exit behavior because it does not end the relation with the local community authorities, nor does it end the use of their services. Yet, because we were unclear about the reasons behind this type of move, we decided to eliminate this group from further analyses. 
Table 1

Means, Standard Deviations, and Correlations Among the Factors of the Exit-Voice Model

\begin{tabular}{|c|c|c|c|c|c|c|}
\hline & $M$ & $S D$ & $\begin{array}{l}\text { Dissatis- } \\
\text { faction }\end{array}$ & $\begin{array}{l}\text { Depen- } \\
\text { dence }\end{array}$ & Exit & Voice \\
\hline Dissatisfaction & 2.31 & 0.94 & - & $-.06 *$ & $.13 * * *$ & $.08 * *$ \\
\hline Dependence & 2.78 & 1.04 & & - & $-.27^{* * *}$ & $.26 * * *$ \\
\hline Exit & 1.70 & 0.91 & & & - & $-.07 * *$ \\
\hline Voice & 1.25 & 0.89 & & & & - \\
\hline
\end{tabular}

${ }^{*} p<.05 .{ }^{* *} p<.01 .{ }^{* * *} p<.001$.

Final sample. The final sample to test our hypotheses consisted of 1,304 households. ${ }^{7}$ This excluded 114 households whose members exhibited an intention to move but only within their community as well as 111 households with at least one missing value on the relevant survey questions.

\section{Results}

The data analysis proceeded in three stages. In the first stage, we performed descriptive statistics on the data, inspecting the means and standard deviations for the relevant constructs: satisfaction, dependence, exit, and voice. In the second phase, we conducted correlation analyses between these constructs. Finally, hierarchical regression analyses were performed to examine our hypotheses regarding the impact of dissatisfaction and dependence, as well as (for exploratory purposes) the interaction between these factors on residential exit and voice strategies. Following a standard regression procedure (Aiken \& West, 1991) and before conducting these regression analyses, we centered the scores on the variables and included the deviation scores so as to control for any nonessential correlations between predictors and their interaction.

\section{Descriptive Results}

A summary of the means and standard deviations of the four factors (dissatisfaction, dependence, exit, and voice) is presented in Table 1. This table shows a good variance in scores for each of the constructs, including the composed dependence and voice variables. A frequency analysis on the dependence variable

${ }^{7}$ We checked whether there were any differences in average ratings on the dependent measures between households in the three cities (London, Manchester, and Birmingham). However, this was not the case; therefore, our analyses were conducted with the overall sample of 1,304 households. 


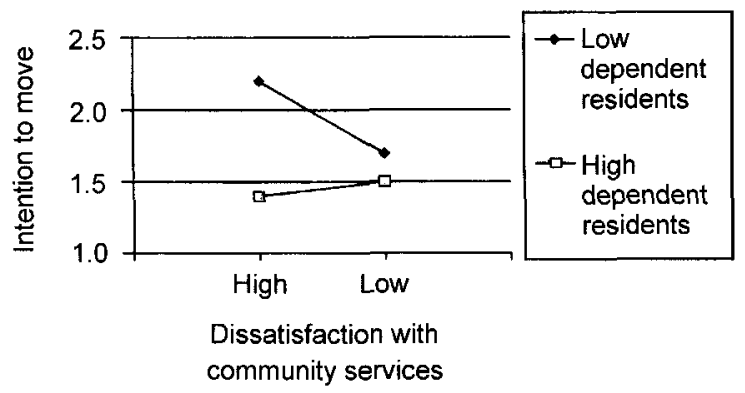

Figure 1. How dissatisfaction with community services affects moving intention for weakly and highly dependent residents. The exit scale ranges from 1 (definitely stay) to 4 (definitely move).

reveals a normal distribution of scores. A score of 0 (weak dependence) was obtained by $3 \%$ of the participants, a score of 1 by $10 \%$, and a score of 2 by $25 \%$; whereas scores of 3,4 , and 5 (strong dependence) were obtained by $36 \%, 23 \%$, and $2 \%$ of the participants, respectively.

Subsequently, we calculated the correlations between the factors in our theoretical model. These results are depicted in Table 1. As can be seen from this table, all correlation coefficients are statistically significant, although the absolute size of these correlations is moderate.

\section{Predicting Exit Intention}

In the first hierarchical analysis (Table 2), we regressed the exit intention $(1=$ definitely stay, 4 = definitely move) onto the two predictors, dissatisfaction and dependence (Model 1), and their interaction (Model 2). This analysis reveals that the model factors together accounted for $10 \%$ of the variance in moving intentions As predicted, exit intentions were positively associated with dissatisfaction with community services $(\beta=.12, p<.001)$. Thus, more dissatisfied residents were more likely to want to leave the community.

Furthermore, exit intentions were negatively associated with dependency on the community $(\beta=-.27, p<.001)$. Thus, the less dependent residents were more likely to consider leaving the community.

In addition, looking at the interaction effects, it appears that there was an interactive effect for dissatisfaction and dependence $(\beta=-.05, p<.05)$. This interaction is displayed in Figure 1, using a standard procedure for plotting interactions between continuous predictors (Aiken \& West, 1991). ${ }^{8}$ This graph reveals

${ }^{8}$ To this end, the scores for each of the two predictors were centered and, using the original $B$ weights, we plotted the regression lines for the weakly and highly dependent residents separately, the results of which are shown in Figure 1. 
Table 2

Predicting Exit and Voice From Model Factors in Hierarchical Regression

\begin{tabular}{lcccc}
\hline \multicolumn{1}{c}{ Criteria } & $\beta$ & $\begin{array}{c}\% \text { of } \\
\text { variance }\end{array}$ & $F$ & $d f$ \\
\hline Exit & & & & \\
$\quad$ Model 1 & 9 & 63.85 & 2,1302 \\
$\quad$ Satisfaction & $.12^{* * *}$ & & & \\
$\quad$ Dependence & $-.27^{* * *}$ & & & \\
Model 2 & & 10 & 44.09 & 3,1301 \\
$\quad$ Satisfaction & $.12^{* * *}$ & & & \\
$\quad$ Dependence & $-.27^{* * *}$ & & & \\
$\quad$ Satisfaction $\times$ Dependence & $-.05^{*}$ & & & \\
Voice & & & & \\
Model 1 & & 8 & 51.83 & 2,1302 \\
$\quad$ Satisfaction & $.10^{* * *}$ & & & \\
$\quad$ Dependence & $.26^{* * *}$ & & & \\
Model 2 & & 8 & 34.69 & 3,1301 \\
$\quad$ Satisfaction & $.10^{* * *}$ & & & \\
$\quad$ Dependence & $.26^{* * *}$ & & & \\
$\quad$ Satisfaction $\times$ Dependence & -.02 & & & \\
\hline
\end{tabular}

${ }^{*} p<.05 .{ }^{* * *} p<.001$.

that there was no difference in exit intentions between weakly and strongly dependent residents if they were satisfied. However, if they were dissatisfied, weakly dependent residents had stronger exit intentions than did strongly dependent residents. A different way to look at this effect is by comparing the slopes for the weakly and strongly dependent residents. For residents with a weak community dependence, the slope is significantly different from zero, $t(530)=$ $2.76, p<.01$; whereas for strongly dependent residents, the slope is nonsignificant, $t(772)<1$. This result shows that the exit strategy is more preferred when dissatisfaction is combined with weaker dependence (i.e., greater exit opportunities).

Finally, we performed separate regression analyses with each of the demographic factors that formed the dependence construct. These analyses reveal that each variable, except the presence of school-age children $(\beta=-.03, p=.28)$, uniquely predicted exit intentions, and each in the hypothesized direction. All of 
these factors inhibited the exit intention. The strongest predictors were age $(\beta=$ $-.27, p<.001)$ and home ownership $(\beta=-.22, p<.001)$, followed by no paid employment $(\beta=-.14, p<.001)$ and living with a partner $(\beta=-.07, p<.05)$. Furthermore, there was a significant interaction between dissatisfaction and age $(\beta=$ $-.12, p<.06$ ), indicating that particularly younger residents considered exiting if they were dissatisfied.

\section{Predicting Voice Behaviors}

In a second analysis, we regressed voice $(0=$ no action, $3=$ all three actions $)$ onto the predictors in the model (Table 2). First, this analysis reveals that the model accounted for $8 \%$ of variance in voice decisions. Second, this analysis shows that voice was positively associated with dissatisfaction with community services $(\beta=.10, p<.001)$, indicating more voice when residents were less satisfied with community services.

Voice was associated with a greater dependency on the community $(\beta=.26$, $p<.001)$. As predicted, highly dependent residents were more likely to have used voice, compared with weakly dependent residents. There was no evidence for a significant interaction between dissatisfaction and dependence on voice $(\beta=$ $-.02, p=.52$ ).

Furthermore, we performed separate analyses with each demographic factor that contributed to the dependence construct. Similar to the previous analyses on exit intentions, these analyses reveal that each variable, except the presence of school-age children $(\beta=.02, p=.35)$, uniquely predicted voice and each in the hypothesized direction. All of these factors enhanced the use of voice. Again, the strongest predictors were age $(\beta=.23, p<.001)$ and home ownership $(\beta=.23, p<$ $.001)$, followed by living with a partner $(\beta=.11, p<.001)$ and no paid employment $(\beta=.08, p<.01)$. Finally, there was a marginally significant interaction between dissatisfaction and having school-age children $(\beta=.14, p<.06)$, indicating that residents with school-age children had used voice when they were dissatisfied.

Finally, we conducted separate logistic regression analyses for each of the three voice activities (voting in a local election, contacting the Council, dealing with Council employees), with dissatisfaction and the overall dependence score as predictors. Recall that the reliability of the voice construct was modest. Therefore, we were interested to find out whether the same results would be obtained across the different voice strategies. For the latter two voice activities (contacting a councilor and dealing with Council employees), the results show that, as predicted, both dissatisfaction $\left(\chi^{2}[1, N=1,304]=10.12\right.$ and $\left.12.18, p<.001\right)$ and dependence $\left(\chi^{2}[1, N=1,304]=7.94\right.$ and $\left.5.00, p<.05\right)$, contributed uniquely to predicting voice. There were no significant interaction effects, $\chi^{2}(1, N=1,304)<$ 1. Voting, however, was predicted by dependence, $\chi^{2}(1, N=1,304)=18.21, p<$ .001 , but not by dissatisfaction with community services, $\chi^{2}(1, N=1,304)<1$ : 
there was no significant interaction, $\chi^{2}(1, N=1,304)<1$. This latter difference is noteworthy and will be addressed in the Discussion.

\section{Discussion}

In this article, we examined problem solving within residential communities. We made a conceptual distinction between two different residential action strategies: the exit of residential mobility versus the voice of political action. The exitvoice framework was used to understand residents' responses to dissatisfaction with local community services in three large metropolitan communities in the United Kingdom.

\section{Antecedents of Exit and Voice Strategies}

One of the central aims of the study was to gain insight into both the structural and psychological conditions that shape exit and voice strategies within residential communities. Inspired by interdependence theory (Kelley \& Thibaut, 1978; Rusbult \& Van Lange, 1996), we proposed that exit-voice reactions would be influenced by two different properties: degree of dissatisfaction with community services, and dependence on them.

First, in line with our prediction, exit and voice tendencies were stronger the more dissatisfied residents reported that they were with the overall provision of community services (e.g., social, health and leisure services, the police). Although we were interested primarily in residents' current satisfaction levels, responses might well have been influenced by the discrepancy between the experienced quality and their perceptions about what the quality should be or what it had been before (Kelley \& Thibaut, 1978). For example, in light of the amount of council taxes they paid compared with other communities, residents might have believed that they were entitled to a better quality of service. Accordingly, feelings of entitlement or relative deprivation (Crosby, 1976) might well have contributed to the experienced dissatisfaction of residents, thereby reinforcing exit and voice reactions. In addition, dissatisfaction also might be caused by the perceived discrepancy between the actual state of services and how they were when residents moved into the community. It is important for future research to establish the relative importance of these evaluations. Perhaps exit and voice responses are reinforced when people experience a sudden deterioration in services (e.g., as a result of vandalism or increased crime), as opposed to communities in which services are structurally poor and residents have gotten used to them.

Second, consistent with predictions, exit-voice strategies also were influenced by residents' dependency on the community and its services. The level of dependency was measured by aggregating various demographic factors that are known to restrict exit opportunities within communities (age, home ownership, low income, married or cohabiting, and presence of school-age children; Rossi, 
1980). Dependency is, therefore, functionally equivalent to a lack of viable exit alternatives (i.e., the comparison level of alternatives; Kelley \& Thibaut, 1978). We found that, regardless of actual dissatisfaction, residents were, overall, more likely to use their voice to authorities to the extent that they were more greatly dependent on their community's provision of services. Weakly dependent residents, in contrast, exhibited a greater desire to move out of the community. Further analyses reveal that each of the demographic variables uniquely contributed to these results, except for the presence or absence of school-age children. Parents with school-age children were found to use voice only when they were dissatisfied with local services.

It can thus be concluded that residential action strategies are directly affected by opportunities for residents to move out of the neighborhood. That is, even when residents are currently satisfied with the provision of community services, those with viable exit opportunities (e.g., those who do not own a house, who are single, who have a good income) are more likely to consider leaving. This is perhaps not all that surprising because it is quite common for residents to move between communities, particularly within metropolitan areas, and people do so for numerous reasons, just one of them having to do with the state of community services. Of greater interest is that residents without viable exit opportunities used their voice structurally more to local authorities, regardless of their actual dissatisfaction with these services. Perhaps by voicing, they indicate to authorities that for them it is important that the current service quality be maintained in the future. Hence, by using voice, they keep authorities "on their toes," thereby possibly preventing a deterioration of community services (Dowding et al., 2000; Hirschman, 1970).

It was interesting to see that this pattern of results, as shown by the logistic regression analyses, was obtained for three quite different voice activities: voting in a local election, contacting the local councilor, and dealing with Council employees. The first is an example of a traditional collective activity, whereas the latter two are more or less spontaneous actions, displayed individually rather than collectively. Residential dependence can thus account for a range of voice strategies to overcome community problems.

In contrast, residents' dissatisfaction with community services only predicted the spontaneous, individual voice activities, but it was not related to voting in a local election. This suggests that residents only engage in spontaneous voice activities if they are truly unhappy about certain events or situations within their community. Yet, there are several reasons why people might choose to vote in a local election; for example, because they see it as their moral duty or because they want to follow a social norm (Kinder, 1998).

Another finding of this research is that dissatisfaction and dependency operated in conjunction in affecting residents' exit intentions, albeit that there was only a marginal improvement in the predictive value of the model, including this 
interaction. Further analyses reveal that exit was most likely among residents who were dissatisfied with community services, but who had an opportunity to leave (i.e., weak dependence). This result is quite consistent with research carried out in a metropolitan community in the United States in the 1960s (Orbell \& Uno, 1972), which found that, compared to Black residents, White residents (i.e., a group with more viable exit options) responded to inner-city problems by exiting to suburban areas.

\section{Limitations and Directions for Future Research}

Before closing, we wish to note two limitations of the present study and suggest new directions for research into community action. The primary limitation is that our theoretical model accounted for a relatively modest portion of variance in both exit and voice strategies. There are several reasons for this. First, there are a myriad of different factors that determine why residents move, besides the poor state of local community services (Rossi, 1980). Residents might move out of the community because of their jobs or a change in their private circumstances (e.g., marriage, divorce). Or, they might move simply because they can get a nicer house elsewhere. Similarly, residents might contact a local councilor for various reasons; for example, to ask for information about a particular community service.

Second, we concentrated only on the use of behavioral strategies. Yet, a large portion of the residential population, although they could be dissatisfied with community services, probably does nothing about the situation. Sometimes residents simply wait and see whether community services improve by themselves, and other times they do nothing because they do not care too much about them. In previous research in social psychology, such behavioral responses have been labeled loyalty and neglect, respectively (Farrell, 1983; Rusbult \& Zembrodt, 1983). Although it is difficult to see how these could actually help to solve people's community problems, hence how they contribute to improving residential outcomes, they might be taken into account in future research.

In this regard, it would be interesting to see what distinguishes active from passive residents. Perhaps the latter group of people either does not realize that they have a voice opportunity, they do not know to whom they should raise their voices, or they do not believe that local authorities will be responsive to their complaints (Folger, 1977). Thus, the perceived efficacy of voice might be an important predictor of residential action. Furthermore, demographic factors such as age or personality factors such as individual differences in self-esteem (Brockner et al., 1998), assertiveness, or attribution style perhaps play a role as well in determining who exits or voices, and who remains silent in response to dissatisfaction with services.

A third reason for the relatively modest explanatory power of the model (particularly voice) pertains to the complexity of the voice strategy (Dowding et al., 
2000). In the present study, we concentrated on three different voice activities, but voice can be expressed in many other ways as well. Voice can be expressed either individually or collectively, but also in more or less constructive ways (Hagedoorn, 1998; Wright, Taylor, \& Moghaddam, 1990). For example, residents can engage in problem-solving actions that threaten the social order within the community, such as through a petition, demonstration, boycott, or even a riot. Further research is needed to develop a systematic classification of different voice activities in residential communities and when they are likely to be used.

A secondary limitation of the study pertains to the fact that it was based on a cross-sectional survey; hence, it does not allow for drawing causal inferences between the variables. For example, residents who indicated having used voice to local authorities might have regarded this as an indication of their dissatisfaction with services, rather than the other way around (cf. cognitive dissonance; Festinger, 1957). Research is needed that employs a longitudinal approach to examine the temporal aspects of both voice and exit, and to study actual exit behavior as well as intended exiting, as was done in our study. It might well be that residents, when they experience dissatisfaction with services, try out voice first and resort to exit only if local authorities are repeatedly unresponsive to their complaints (Dowding et al., 2000).

\section{Practical Implications}

The exit-voice framework yields some important implications for the stability and welfare of residential communities. This model suggests that in areas where residential mobility is limited, fewer problems are likely to emerge because the level of political and community activity will be higher than in areas where residential mobility is fairly common. In communities from which exiting is relatively difficult (i.e., more stable communities), there will be a stronger commitment from residents to prevent a deterioration of neighborhood services. In less stable communities, however, local authorities could not afford any decline in services, otherwise they will lose residents. Indeed, when residents respond to community problems by leaving, they no longer make efforts, either actively (e.g., via voice) or passively (e.g., via local taxes), to maintain a satisfactory level of community services. This is likely to produce a further service decline, which might well be followed by more exits from other residents. This dynamic, destabilizing process might help to understand the relatively poor state of many innercity neighborhoods in otherwise wealthy cities in the United Kingdom and United States.

How then could community action be encouraged within neighborhoods? First, it is important that local authorities have adequate procedures in place to enable citizens to voice their dissatisfaction (Folger, 1977; Tyler \& Lind, 1992). One way to achieve this is via the introduction of complaint procedures, the 
assignment of contact officers, and holding regular local elections or referenda. Such procedures increase the likelihood that residents stay, although they might be temporarily dissatisfied with the community services. If adequate voice procedures are lacking or authorities are not responsive enough to complaints, residents might choose to leave the community and move elsewhere. This, however, would happen only if residents have viable exit opportunities. Therefore, a second, more drastic way to prevent residential exit is to increase the costs of leaving; that is, to increase residential dependence. This could be achieved, for example, by giving local council tax benefits to longtime residents so that it is less attractive for them to leave their residential community.

In a large, cross-sectional survey, we examined two distinct strategies for community problem solving: the exit of residential mobility versus the voice of political action. Using an interdependence theory (Kelley \& Thibaut, 1978) framework, we predicted and found that exit and voice responses were enhanced the greater the dissatisfaction with the state of local community services. Furthermore, while exit was the dominant strategy among residents who were weakly dependent on these services, highly dependent residents used voice more frequently. To tackle the decline of residential communities and foster community stability, our findings suggest that local authorities should either increase the costs of exiting or promote residential voice.

\section{References}

Adams, J. S. (1965). Inequity and social exchange. In L. Berkowitz (Ed.), Advances in experimental social psychology (Vol. 2, pp. 267-299). New York, NY: Academic Press.

Aiken, L. S., \& West, S. G. (1991). Multiple regression: Testing and interpreting interactions. Newbury Park, CA: Sage.

Brockner, J., Heuer, L., Siegel, P. A., Wiesenfeld, B., Martin, C., Grover, S., Reed, T., \& Bjorgvinsson, S. (1998). The moderating effect of self-esteem in reaction to voice: Converging evidence from five studies. Journal of Personality and Social Psychology, 75, 394-407.

Crosby, F. (1976). A model of egoistic relative deprivation. Psychological Review, $83,85-113$.

Dawes, R. M. (1980). Social dilemmas. Annual Review of Psychology, 31, 169-193.

Dowding, K., John, P., Mergoupis T., \& Van Vugt, M. (2000). Exit, voice, and loyalty: Analytical and empirical developments. European Journal of Political Research, 37, 469-495.

Farrell, D. (1983). Exit, voice, loyalty, and neglect as responses to job dissatisfaction: A multidimensional scaling study. Academy of Management Journal, 26, 596-607.

Festinger, L. (1957). A theory of cognitive dissonance. Evanston, IL: Row Peterson. 
Folger, R. (1977). Distributive and procedural justice. Combined impact of voice and improvement on experienced inequity. Journal of Personality and Social Psychology, 35, 108-119.

Hagedoorn, M. (1998). Employees' reactions to dissatisfying situations: Mullet method research with justice-based predictors. Unpublished doctoral dissertation, University of Groningen, The Netherlands.

Hirschman, A. O. (1970). Exit, voice, and loyalty: Responses to decline in firms, organizations, and states. Cambridge, MA: Harvard University Press.

Hollander, E. P. (1985). Leadership and power. In G. Lindzey \& E. Aronson (Eds.), The handbook of social psychology (pp. 485-537). New York, NY: Random House.

Kelley, H. H., \& Thibaut, J. W. (1978). Interpersonal relations: A theory of interdependence. New York, NY: John Wiley \& Sons.

Kinder, D. (1998). Opinion and action in the realm of politics. In D. Gilbert, S. Fiske, \& G. Lindzey (Eds.), The handbook of social psychology (pp. 485-537). New York, NY: McGraw-Hill.

Klandermans, P. G. (1997). The social psychology of protest. Oxford, UK: Blackwell.

Komorita, S. S., \& Parks, C. D. (1994). Social dilemmas. Dubuque, IA: Brown \& Benchmark.

Mergoupis, T., Dowding, U., \& John, P. (2000). Problems of residential mobility as a marketlike mechanism in local government. London, UK: London School of Economics, CNPSS Discussion Paper DPU6/00.

Orbell, J. M., \& Uno, T. (1972). A theory of neighborhood problem-solving: Political action versus residential mobility. American Political Science Review, 66, 471-489.

Rossi, P. (1980). Why families move: A study in the social psychology of urban residential mobility. Beverley Hills, CA: Sage.

Rusbult, C. E., \& Lowery, D. (1985). When bureaucrats get the blues: Responses to dissatisfaction among federal employees. Journal of Applied Social Psychology, 15, 80-103.

Rusbult, C. E., \& Van Lange, P. A. M. (1996). Interdependence processes. In E. T. Higgins \& A. Kruglanski (Eds.), Social psychology: Handbook of basic principles (pp. 564-596). New York, NY: Guilford.

Rusbult, C. E., \& Zembrodt, I. M. (1983). Responses to dissatisfaction in romantic involvements: A multidimensional scaling analysis. Journal of Experimental Social Psychology, 19, 274-293.

Tiebout, C. M. (1956). A pure theory of local expenditures. Journal of Political Economy, 64, 416-424.

Tyler, T. R., \& Degoey, P. (1995). Collective restraint in social dilemmas: Procedural justice and social identification effects on support for authorities. Journal of Personality and Social Psychology, 69, 482-497. 
Tyler, T. R., \& Lind, E. A. (1992). A relational model of authority in groups. In M. Zanna (Ed.), Advances in experimental social psychology (Vol. 25, pp. 115-191). New York, NY: Academic Press.

Tyler, T. R., \& Smith, H. J. (1998). Social justice and social movements. In D. Gilbert, S. T. Fiske, \& G. Lindzey (Eds.), The handbook of social psychology (pp. 595-632). New York, NY: McGraw-Hill.

Van Vugt, M., \& De Cremer, D. (1999). Leadership in social dilemmas: The effects of group identification on collective actions to provide public goods. Journal of Personality and Social Psychology, 76, 587-599.

Van Vugt, M., Snyder, M., Tyler, T., \& Biel, A. (2000). Cooperation in modern society: Promoting the welfare of communities, states, and organisations. London, UK: Routledge.

Wright, S. C., Taylor, D. M., \& Moghaddam, F. M. (1990). Responding to membership in a disadvantaged group: From acceptance to collective protest. Journal of Personality and Social Psychology, 58, 994-1003. 